\title{
RELIGIOSIDADE, JUVENTUDE E SEXUALIDADE: ENTRE A AUTONOMIA E A RIGIDEZ ${ }^{1}$
}

\author{
Cristiane Gonçalves da Silva \\ Alessandro Oliveira Santos ${ }^{\#}$ \\ Daniele Carli Licciardi" \\ Vera Paiva
}

\begin{abstract}
RESUMO. Este artigo descreve como jovens religiosos e autoridades religiosas das respectivas comunidades compreendem a sexualidade, considerando suas experiências pessoais e como membros de comunidades religiosas. A análise pretende contribuir para que políticas públicas dedicadas à promoção da saúde sexual da juventude considerem a religiosidade no contexto de um Estado laico e da promoção do direito à prevenção. Foram realizadas 26 entrevistas abertas e semidirigidas em diferentes comunidades da região metropolitana da cidade de São Paulo (comunidade Católica, de Umbanda, do Candomblé e de diferentes denominações Evangélicas) sobre iniciação sexual, casamento, gravidez, contracepção e prevenção das DSTs/aids, homossexualidade, aborto e direitos humanos. Observou-se como jovens e autoridades religiosas convivem com a tensão entre tradição e modernidade e os distintos discursos sobre a sexualidade. Como sujeitos religiosos (do discurso religioso) e sujeitos sexuais (de discursos sobre sexualidade), devem ser incorporados pelos programas como sujeitos de direito nos termos de sua religiosidade.
\end{abstract}

Palavras-chave: juventude, religião, sexualidade.

\section{RELIGIOSITY, YOUNG PEOPLE AND SEXUALITY: BETWEEN AUTONOMY AND RIGIDITY}

\begin{abstract}
Current article describes how religious young people and the religious authorities of their communities understand sexuality. Knowledge is based on personal experiences as well as members of a religious community. Analysis investigates the manner public policies devoted to the sexual health of young people take religiosity into account within the context of a lay state and within the context of the right to disease prevention. Twenty-six open and half-structured interviews were undertaken in different communities (Catholic communities, Umbanda, Candomblé and different Evangelic denominations) of the metropolitan region of São Paulo SP Brazil. Interviews covered sexual initiation, marriage, pregnancy, contraception and STD/Aids prevention, homosexuality, abortion and human rights. It has been reported that youth and religious authorities experience the tension between tradition and modernity and distinct discourses on sexuality. As religious subjects (of the religious discourse) and sexual subjects (of sexuality discourses), they should be integrated into programs as subjects with their rights, within their own religiosity terms.
\end{abstract}

Key words: Young people, religion, sexuality.

\footnotetext{
1 Apoio: U.S. National Institute of Child Health and Human Development, PROSARE/CEBRAP - Fundação Mac Arthur e Capes. Esse artigo deriva da pesquisa "Jovens e religião - sexualidade e direitos entre lideranças católicas, evangélicas e afrobrasileiras" realizada por meio de edital PROSARE/CEBRAP 2006. Integra a pesquisa "Respostas Religiosas ao HIV/AIDS no Brasil" (financiamento U.S. National Institute of Child Health and Human Development, 1 R01 HD05118-01, coordenada por Richard Parker/ (Columbia University). Coordenam as equipes locais: Rio de Janeiro, Veriano Terto Jr. (Associação Brasileira Interdisciplinar de AIDS); São Paulo, Vera Paiva (Universidade de São Paulo); Porto Alegre, Fernando Seffner (Universidade Federal do Rio Grande do Sul) e Recife, Luís Felipe Rios (Universidade Federal de Pernambuco). Informações: religiao@abiaids.org.br ou www.abiaids.org.br. Cristiane Gonçalves da Silva foi bolsista de doutorado da CAPES em 2007 e 2008.

* Doutoranda em Psicologia Social, Instituto de Psicologia da Universidade de São Paulo e Núcleo de Estudos para Prevenção da Aids (NEPAIDS), São Paulo.

\# Doutor em Psicologia, Fundação Escola de Sociologia e Política de São Paulo, NEPAIDS, São Paulo.

II Graduada em Psicologia. NEPAIDS, São Paulo.

æ Doutora. Professora no Instituto de Psicologia/USP e NEPAIDS, São Paulo.
}

Autores convidados. 


\title{
RELIGIOSIDAD,JUVENTUD Y SEXUALIDAD: ENTRE LA AUTONOMIA Y LA RIGIDEZ
}

\begin{abstract}
RESUMEN. Este artículo describe como los jóvenes religiosos y sus autoridades religiosas comprenden la sexualidad, embasados en su experiencia personal y como miembro de comunidades religiosas. El análisis pretiende contribuir para políticas públicas de promoción de salud, en le contexto del estado laico y de la promoción y protección del derecho a la prevención. Veintiséis entrevistas abiertas y semi-dirigidas fueron realizadas junto a diferentes comunidades religiosas de la región metropolitana de São Paulo (católicas, religiones de matriz afro-brasilera Umbanda y Candomblé y diferentes denominaciones Evangélicas) sobre: iniciación sexual, casamiento, embarazo, aborto, contracepción y prevención de DST/SIDA, homosexualidad y derechos humanos. Se ha observado como los jóvenes y sus autoridades religiosas han convivido con la tensión entre tradición y modernidad, y con los distintos discursos sobre la sexualidad. Como sujetos religiosos (del discurso religioso) y sujetos sexuales (del discurso sobre sexualidad), deben ser incorporados por los programas como sujetos de derecho en los termos de su religiosidad.
\end{abstract}

Palabras-clave: Juventud, religión, sexualidad.

Vários estudos no campo de gênero e sexualidade vêm explorando a importância do universo religioso como instância reguladora das sexualidades brasileiras, em interação com diversos outros discursos disseminados pela mídia, como os de inspiração tecnocientífica no campo da sexologia ou da prevenção da aids (Citelli, 2004; Cunha, 2000; Heilborn, 2006; Parker, 1991). Cresce a predominância de uma ideologia que valoriza a individualidade e a secularização, ressignifica as práticas sociais, desloca as fronteiras das instâncias que compõem a sociedade (Burity, 2001; Gruman, 2005) e modifica a gestão da religiosidade sobre a sexualidade. A esfera religiosa tem renovado seus discursos sobre o gênero e a sexualidade, mantendo-se como dimensão sociocultural relevante no processo de socialização para a normatividade sexual.

Observa-se que a forte tradição católica brasileira foi sendo modificada nas últimas décadas e transformada em uma quase explosiva polissemia religiosa (Brandão, 2004). Além disso, vários estudos têm demonstrado que entre pessoas pertencentes à mesma denominação religiosa não há, necessariamente, unidade na vivência. No seio da considerável diversidade religiosa brasileira atual pode ser encontrada uma dinâmica conjugação de códigos de diferentes religiões, freqüentemente, numa mesma família - onde o pai é católico, a mãe é evangélica e os filhos são de religiões afro-brasileiras, por exemplo. As pessoas, portanto, escolhem como viver sua religiosidade. Nesse contexto, como coloca Duarte (2006), cada discurso religioso codifica as atitudes morais consideradas razoáveis para o seu rebanho, cabendo aos fiéis comparar as codificações disponíveis e se aproximar da congregação que dialoga com sua própria disposição moral.
Esse mesmo autor chama de "subjetivismo" o valor estruturante da religiosidade contemporânea que reforça a primazia da escolha pessoal do sujeito (Duarte, Jabor, Gomes \& Luna, 2006). O "sujeito religioso" é o protagonista de sua religiosidade, é o ator histórico da sua religião de escolha e emprega em seu cotidiano um sistema de crenças que foram propagadas pelas autoridades religiosas, porém não $\mathrm{o}$ faz sem modificações, recriando-o para sua experiência (Watanabe, 2005). A relação de autoridade que os fiéis estabelecem com suas lideranças e referências religiosas, segundo Farris (2008), serve às necessidades individuais e sociais da pessoa e do grupo, e mesmo as escolhas das autoridades religiosas (padre, educadores, reverendos, pastores, diaconisas, pais e mães-de-santo) refletem processos cognitivos, emocionais e sociais. Pesquisas feitas sob o olhar do fiel permitirão acesso à religião viva, à experiência cotidiana com a religião, ou seja, à religiosidade, e não apenas aos sistemas de dogmas e valores propagados pela hierarquia que interpreta a tradição (a religião).

A religiosidade tem sido indicada como uma alternativa importante de sociabilidade e lazer para jovens e adolescentes (Santos \& Mandarino, 2005). Durante um dos períodos da vida em que os scripts que orientam a experiência da sexualidade e os vários roteiros para a vida amorosa, conjugal e reprodutiva ficam bastante salientes, os valores compartilhados com a família ou a comunidade mais próxima são especialmente relevantes. Diante desses contextos, quais seriam os efeitos deste subjetivismo religioso na socialização sexual dos jovens?

A última pesquisa nacional sobre sexualidade demonstrou que o sentido da iniciação sexual e crescimento do uso do preservativo na primeira relação 
sexual tem sido diferente entre grupos de diferentes religiões (Paiva, Calazans, Venturi \& Dias, 2008). Embora a promoção do preservativo e a educação sexual nas escolas fossem apoiadas por mais de $90 \%$ dos brasileiros, independentes de sua religião, poucas iniciativas no campo dos programas de DSTs/aids conseguiram abordar sistematicamente os jovens religiosos em diálogo com suas crenças e nos seus próprios termos, garantindo o seu direito à prevenção, como o acesso ao preservativo e à informação de como utilizá-lo.

Mais recentemente, várias iniciativas junto à juventude têm trabalhado a promoção da saúde sexual no campo da prevenção das DSTs e HIV, definindo como principal resultado de projetos e programas o fortalecimento do sujeito sexual (Paiva, 1999) compreendido como sujeito de direitos sexuais e do direito à prevenção (Paiva, 2005; Paiva, Pupo \& Barboza, 2006). Essa abordagem conceitual-metodológica pressupõe que a esfera da sexualidade se organiza socioculturalmente e não existe uma sexualidade essencial ou um sentido natural para o "desenvolvimento adequado" da sexualidade. Nesse quadro observa-se que o discurso da prevenção disputa a atenção do sujeito com vários outros discursos sobre a sexualidade - por exemplo, os discursos religiosos ou produzidos pelos movimentos sociais, como o de lésbicas, gays, bissexuais, travestis e transexuais. Se nenhuma normalidade técnica justificaria a normatização da vida sexual dos jovens, a literatura tem discutido que o sucesso dos programas de prevenção das DSTs/aids depende do diálogo com os sujeitos nos termos de sua vida cotidiana e de seu cenário sociocultural (Paiva, Ayres \& França Jr, 2003; Paiva, 2005). Os projetos de pesquisa que resultaram neste artigo buscaram esse diálogo.

Este artigo buscou compreender como jovens religiosos e suas autoridades religiosas (padres, educadores religiosos, reverendos, pastores, diaconisas, pais e mães de santo) concebem a sexualidade, focalizando os significados e os sentidos atribuídos às experiências sexuais antes do casamento, ao início da vida sexual, à homossexualidade, à gravidez não planejada e ao aborto.

\section{MÉTODO}

Analisaremos 26 entrevistas semi-estruturadas e em profundidade realizadas com 8 autoridades religiosas e 18 jovens religiosos, rapazes e moças, de 9 comunidades das matrizes afro-brasileira (Candomblé e Umbanda), Católica e Evangélica ${ }^{2}$ (históricas e pentecostais). As autoridades religiosas entrevistadas aprovaram ou indicaram diretamente os jovens de sua comunidade que foram, então, entrevistados. As entrevistas abordaram informações e opiniões sobre a iniciação sexual, contracepção, aborto, homossexualidade, direitos humanos, as doenças sexualmente transmissíveis e a prevenção da aids, investigadas a partir de cenas densamente descritas que exploravam o posicionamento de sua comunidade religiosa sobre os referidos temas.

As primeiras autoridades entrevistadas foram indicadas por participantes do Grupo de Trabalho Religiões e Aids ${ }^{3}$, composto por religiosos de várias denominações, ativistas e técnicos de governos de municípios e do Estado de São Paulo envolvidos no enfrentamento da epidemia de HIV/aids. Os primeiros entrevistados indicaram, então, outras lideranças religiosas que consideraram sensibilizadas para o tema da aids.

Cada entrevistado assinou termo de consentimento ou assentimento livre e esclarecido antes das entrevistas, que foram gravadas, transcritas e discutidas segundo análise temática de conteúdo. As pesquisas, que resultaram nesse artigo, foram aprovadas por Comitês de Ética em Pesquisa ${ }^{4}$ a que foram submetidas. A idade, sexo e vinculação religiosa dos entrevistados estão descritos na Tabela 1.

Tabela 1. Entrevistados Caracterizados por Matriz, Posição na Comunidade Religiosa, Sexo e Idade.

\begin{tabular}{llcc}
\hline Matriz Religiosa & Autoridades - Número e posição/ comunidade religiosa & Sexo & Idades (em anos) \\
\hline Afro-brasileira & 1 mãe-de-santo/Umbanda & $\mathrm{F}$ & 46 \\
(3 entrevistas) & 1 pai-de-santo/Umbanda & $\mathrm{M}$ & 36 \\
Católica & 1 ialorixá/Candomblé & $\mathrm{F}$ & 44 \\
\hline (2 entrevistas) & 1 educadora religiosa/ Católica & $\mathrm{F}$ & 63 \\
Evangélica & 1 padre/Católica & $\mathrm{M}$ & 42 \\
(3 entrevistas) & 1 diaconisa/Assembléia de Deus & $\mathrm{F}$ & 42 \\
& 1 reverendo/Anglicana episcopal & $\mathrm{M}$ & 33 \\
Afro-brasileira & 1 pastor/Adventista da Promessa & $\mathrm{M}$ & 29 \\
(6 entrevistas) & J Jovens & $\mathrm{F}$ & 18 \\
Católica & 2 participante/Umbantes/Candomblé & $\mathrm{F}$ & 15 \\
(6 entrevistas) & 3 participantes/Umbanda & $\mathrm{M}$ & 22 \\
Evangélica & 3 participantes/Católica & $\mathrm{F}$ & $16,18 \mathrm{e} \mathrm{20}$ \\
\hline
\end{tabular}


1 participante/Assembléia de Deus

1 participante/Adventista da Promessa

1 participante/Anglicana Episcopal

1 participante/Assembléia de Deus

1 participante/Adventista da Promessa

$\begin{array}{ll}\text { F } & 25 \\ \text { F } & 21 \\ \text { M } & 23 \\ \text { M } & 22 \\ \text { M } & 18\end{array}$

\section{RESULTADOS E DISCUSSÃO}

As narrativas dos entrevistados, autoridades ou jovens, incorporam tanto os sentidos mais modernos para expressão da sexualidade, que ambicionam a autonomia, como os sentidos enraizados em valores tradicionais da moral religiosa mais heterônoma.

A sexualidade foi reconhecida como foco de interesse e reflexão em todas as comunidades religiosas estudadas. $\mathrm{O}$ sexo foi significado como sagrado, concebido como dádiva de Deus ou presente dos Orixás. Portanto, a religiosidade ganha legitimidade para normatizar o ethos privado e a dimensão sagrada da construção da sexualidade, dos corpos e dos desejos. Há, assim, presença de uma ordem moral e de padrões de conduta considerados ideaise cada denominação religiosa desenvolve modos específicos de orientar comportamentos e de disciplinar seu rebanho. Os entrevistados não se envergonham da sexualidade pois a concebem-na como divinizada se orientada pela moral que valorizam, compartilham e ressignificam.

Para os jovens dos diferentes templos, o espaço religioso foi identificado como importante espaço de identidade e pertencimento. Descreveram seu processo de reconhecimento e escolha das autoridades representadas nos clérigos (pastores, reverendos, diaconisas, etc.), nos padres, nas lideranças leigas ou nas divindades espirituais (caboclos, pretos-velhos, etc.), nos Orixás, na bíblia. A relação de cada fiel com essas autoridades inicia-se com a escolha de "suas" autoridades religiosas, que reconhecem como referências para seu modo de ver o mundo e como possíveis aconselhadores. Em todas as matrizes, entretanto, nem sempre se sentiam confortáveis para falar com as autoridades sobre suas dúvidas e experiências sexuais.

A adesão religiosa dos jovens entrevistados mais frequentemente é descrita como herança familiar. A adesão que "vem de berço" é mais comum entre os jovens evangélicos pentecostais e católicos que herdaram da mãe, do pai ou de ambos a religiosidade cristã. Herdar implica ser socializado pela moral compartilhada pela família e por uma comunidade religiosa. Para as duas jovens do Candomblé, a socialização precoce na religião ocorreu fora da família nuclear, quando foram acolhidas, ainda meninas, pela família-de-santo e pela mãe-de-santo, como "tuteladas", para depois se tornarem filhas-desanto, o que configura uma herança familiar distinta. A jovem umbandista relatou uma herança religiosa dupla: Catolicismo por parte do pai e Umbanda por parte da mãe; seduzida pelos cantos e tambores escolheu a Umbanda.

Os católicos indicaram que podem viver a herança religiosa familiar sem participar mais efetivamente dos rituais e das atividades da comunidade. Essa flexibilidade pode facilitar posicionamentos mais independentes da moral católica exposta pelo Vaticano, como no caso do uso do preservativo e do sexo antes do casamento. Evangélicos pentecostais, por outro lado, enfatizaram que a sua adesão religiosa, mesmo quando iniciada por herança familiar, só foi considerada como uma adesão completa quando fizeram sua própria escolha pessoal. Alguns jovens chegaram a se afastar da religião e escolheram voltar, como num processo de (re)conversão que valoriza de maneira ímpar a religiosidade na vida desses jovens. Os rapazes umbandistas, ao se converterem, deixaram de se considerar "sem religião" para compartilhar novos modos de significação, demonstrando também uma escolha pessoal importante. Relacionaram à sua conversão religiosa mudanças no modo de conceber a sexualidade: o ato sexual passou a ser concebido como um "canal para troca de energia" que merece cuidado e atenção: os fluidos sexuais são energias vitais, não devem ser trocados com qualquer pessoa; valoriza-se a troca de "coisas boas", idéia também presente nas narrativas das autoridades de Umbanda.

“(...) Eu não troco minha energia com qualquer um. (...) Eu acho que o principal ponto na minha religião é a questão da

\footnotetext{
2 Sem espaço para aprofundar as distinções no campo evangélico, estamos nomeando de "evangélicos históricos" os fiéis das religiões derivadas da Reforma Protestante. Chamamos de "evangélicos pentecostais" os adeptos da Assembléia de Deus e os Adventistas da Promessa que, por sua crença apoiada no pentecostalismo, se afastaram do movimento da Reforma.

3 Esse Grupo de Trabalho é coordenado pela Coordenação Estadual de DST/Aids de São Paulo desde 2003.

4 Comitê Nacional de Ética em Pesquisa e Comitê de Ética do Instituto de Psicologia da Universidade de São Paulo.
} 
energia. É a troca da energia que é uma energia sublime, é uma energia criadora, mesmo que seja só por prazer, é criadora" (jovem garota umbandista).

Rapazes e moças católicos entrevistados tinham mais dificuldade em falar de sua própria sexualidade, embora demonstrassem conhecimento sobre métodos contraceptivos e defendessem o uso do preservativo em desacordo com a posição oficial da Igreja Católica. Para os jovens evangélicos pentecostais, assim como para suas autoridades, o exercício da sexualidade deve ser prática permitida apenas no casamento, pois antes disso, sexo significa "pecado", "fornicação". Dádiva de Deus, sexo pode ser bom quando lícito e ruim quando ilícito. Quando lícito, o prazer é obra sagrada e quando ilícito é pecado e deve ser repelido. O casamento assume a posição estratégica de domesticação do desejo sexual e a sua sacralidade, segundo algumas falas, poderia até proteger contra doenças.

Algumas das autoridades cristãs entrevistadas (nenhuma pentecostal) afastaram-se da leitura mais "ao pé da letra" das palavras sagradas e admitiram mudanças, valorizando espaços de reflexão sobre a sexualidade. Não reconheceram de forma explícita, entretanto, a existência de vida sexual ativa entre os jovens de sua comunidade como fizeram as autoridades de Umbanda e Candomblé.

Entre pais e mães das religiões afro-brasileiras, o período ideal para início da vida sexual estava associado a uma "maturidade", pouco definido. Autoridades das igrejas Anglicana e Católica admitiram que a iniciação sexual independe do casamento. Evitaram classificar o sexo antes do casamento como pecado ou falar da abstinência até o casamento como ideal único para vida dos jovens. A iniciação apareceu mais associada à maturidade do que ao casamento, maturidade definida por parâmetros físico-psíquicos e pela capacidade de assumir a responsabilidade pela nova vida.

\footnotetext{
“(...) tem que ter assim uma maturidade para assumir o risco de tudo isso. Normal o homem e a mulher querer um ou outro, a mulher ou o homem querer o sexo, basicamente é normal. Não é a gente que vai definir a idade. Mas a gente diz que é a maturidade de cada uma (...)" (autoridade católica).
}

Com exceção dos evangélicos pentecostais, os jovens manifestaram maior abertura para experiências sexuais antes do casamento. Os jovens afro-brasileiros e católicos consideraram que a sexualidade faz parte do cotidiano juvenil e valorizaram o cuidado, a responsabilidade, o consentimento de ambos os parceiros e também a maturidade para optar pelo início da vida sexual. Destacaram também que a autonomia de cada jovem deve resultar do acesso à informação. Portanto, não há idade certa para iniciar a vida sexual, e sim, condições ideais para que isso aconteça. Especialmente entre os jovens religiosos afro-brasileiros, esta condição incluía a prática de sexo seguro, ou seja, o uso de preservativo.

Alguns jovens evangélicos pentecostais consideraram essa "fase da vida" uma constante ameaça de "queda", ou seja, um período vivido sob risco de ceder às tentações da "fornicação" e relataram que se tendia a antecipar o direito ao sexo casando-se precocemente. Domar hormônios e desejos desafia mais os rapazes. Jovens cristãos atribuíram aos rapazes, ao gênero masculino, um comportamento dominado pelos hormônios. Os hormônios não integraram a narrativa sobre a sexualidade das meninas, parecendo "naturalmente" menos impulsivas, como já se observou em outros estudos (Paiva, 1999).

Os umbandistas apresentaram a maior abertura e disponibilidade para escutar postulados morais e religiosos diferentes dos seus, respeitando a diversidade e posicionando-se mais firmemente como sujeitos religiosos ao reelaborar alguns dogmas da tradição; mas outras autoridades entrevistadas, mesmo sem abandonar a atitude de pregadores de sua verdade, demonstraram valorizar ou aceitar a construção da autonomia e do diálogo entre pessoas que pensam de maneira diferente.

Em relação ao discurso dos direitos sexuais, os líderes religiosos afro-brasileiros demonstraram-se mais abertos, se comparados com as autoridades pentecostais. A posição sobre a homossexualidade apreendida nas narrativas foi a que colocou as religiões em lugares mais extremados. Jovens umbandistas demonstraram maior abertura e respeito pela diversidade sexual, trouxeram inclusive relatos de experiências homoafetivas vividas por eles ou por pessoas muito próximas e entre freqüentadores dos terreiros. Já os jovens evangélicos pentecostais se posicionaram tal como preconizam as leis ditadas por suas autoridades religiosas, ou seja, defendiam que Deus "não aprova" a homossexualidade e que só seria possível haver relação afetivo-sexual entre mulheres e homens. A homossexualidade é concebida como "pecado" e a Igreja forneceria subsídios para que mulheres e homens sejam "libertados" dela, caso queiram se aproximar das leis divinas e de Deus. Os relatos dos evangélicos pentecostais negavam a existência de freqüentadores não heterossexuais em 
seus templos ou em outros templos irmãos. Só seria possível ser evangélico pentecostal identificando-se e sendo identificado como heterossexual. Para as meninas do Candomblé, por outro lado, a homossexualidade teria o estatuto de algo "normal" e era "aceita" por elas e pela comunidade religiosa. À semelhança dos jovens católicos, ao mesmo tempo faziam questão de dizer que não eram homossexuais. Moças e rapazes católicos foram mais enfáticos sobre a necessidade de respeito à diversidade sexual.

De maneiras distintas, autoridades católicas e anglicana entrevistadas admitiram que a homossexualidade era uma questão importante a ser considerada na vida em comunidade. Católicas entrevistadas consideravam a homossexualidade um fato com o qual se deveria lidar sem condenação $a$ priori. A autoridade anglicana relatou que os fiéis estavam abertor para a aceitação de clérigos assumidamente homossexuais atuando em sua Igreja. Entre autoridades religiosas afro-brasileiras, a homossexualidade era concebida a partir dos lugares para os gêneros feminino e masculino, expressos pela mitologia dos Orixás ou por histórias contadas na comunidade.Essas autoridades defendiam códigos e valores religiosos que ajudariam a aceitar a homossexualidade.

O tema da gravidez na adolescência foi abordado espontaneamente por jovens entrevistados e autoridades, preocupados com a gravidez ocorrida fora de hora e que deveria ter sido evitada ("prevenida"). As autoridades indicaram que, para atingir a ideal inexistência de casos de gravidez não planejada entre jovens da comunidade, lançavam mão de estratégias de prevenção e orientação ancoradas tanto no discurso normativo religioso quanto nos discursos técnicocientíficos que concebem a gravidez na adolescência como "perigo", um problema social que interrompe planos (Brandão, 2006; Paiva, 1999, 2005). As diferentes estratégias para lidar com o "problema" representaram bem os dois pontos de vista extremos nesse debate, presentes em todas as matrizes: alguns abordavam a gravidez recomendando e informando sobre métodos contraceptivos, incluindo a camisinha como proteção para evitar gravidez e DST/aids. Preocupam-se em ser diretos e explícitos junto aos pais, defendendo a necessidade de que os jovens adolescentes tenham acesso a preservativos. Outros indicavam o sexo após o casamento (apenas uma autoridade pentecostal utilizou a palavra "abstinência") como sendo o caminho ideal de conduta para jovens.

“(...) a gente procura aconselhar, dar todo apoio, ajuda material, espiritual, psicológica, o que preciso for. (...) A gente tenta prevenir [gravidez não planejada] com palestras (...) a gente entende que só se use camisinha, (...) pra você evitar a gravidez [no casamento] (...) [para solteiros] a gente tenta exatamente o contrário: não use camisinha e não faça sexo" (autoridade da Assembléia de Deus).

Nas falas de todos os religiosos entrevistados a gravidez se definia principalmente por "gerar vida", que é maior obra divina. Essa noção se sobrepunha a outras mesmo quando a gravidez ocorria em momentos inadequados. Mesmo desestruturando, a gravidez produziria uma migração obrigatória ("passagem") da jovem (ou dos jovens) para a condição de um sujeito "responsável" pela gestação de outra vida. Esse processo de mudança justificaria o "acolhimento" como melhor caminho para lidar com esses casos, entendimento que foi comum a todos os entrevistados das diferentes matrizes.

O acolhimento com o respaldo da comunidade deveria estender-se para além do par mãe-filho, em princípio atingindo todos os envolvidos. Os rapazes, entretanto, raramente são mencionados ou diretamente implicados nas cenas dos casos de gravidez, mas as orientações e eventuais procedimentos se aplicariam a eles também. Casos reais e cenas parecem servir como modelos para abordar o tema junto aos outros jovens da mesma comunidade. Para todos os grupos e matrizes, o acolhimento significava "conforto", aliviar o peso do sofrimento das pessoas (pecadores: desviantes, desequilibrados, fracos, doentes). Acolher também guardava o sentido de evitar julgamentos morais nos casos de gravidez não planejada $\mathrm{e}$ considerar o contexto no qual ocorreu. As ordens divinas indicam acolher a todos e a qualquer um,independentemente das causas do seu sofrimento.

Entre os evangélicos pentecostais, entretanto, acolher não significava apagar o fato de que as regras foram desrespeitadas. A gravidez decorrente de uma relação sexual fora ou antes do casamento é falta considerada "mais grave", nas palavras das autoridades e dos jovens. Sendo fruto de relação sexual pré-marital significava "pecado", "fornicação", cuja punição "reparadora" deveria ser o casamento, promotor da "comunhão". Os jovens pentecostais, mesmo quando não concordavam, legitimavam o procedimento dos pastores compreendendo que o casamento, nesses casos, não seria uma imposição, mas uma orientação, um "caminho possível". Conselho ou imposição, o casamento tem o sentido de instrumento reparador que retira os envolvidos da condição de pecadores, 
embora também se encontre entre os entrevistados desse grupo a noção de que, mesmo como ação reparadora de um pecado, o casamento só pode se dar com base no amor, ideal de casamento típico da modernidade ocidental (Bozzon, 2003). Flexibilizase a moral e o casamento é retirado da condição de imposição e castigo; o afeto (ou a falta dele) pode favorecer a autonomia, por parte dos jovens, em relação às escolhas de casamento.

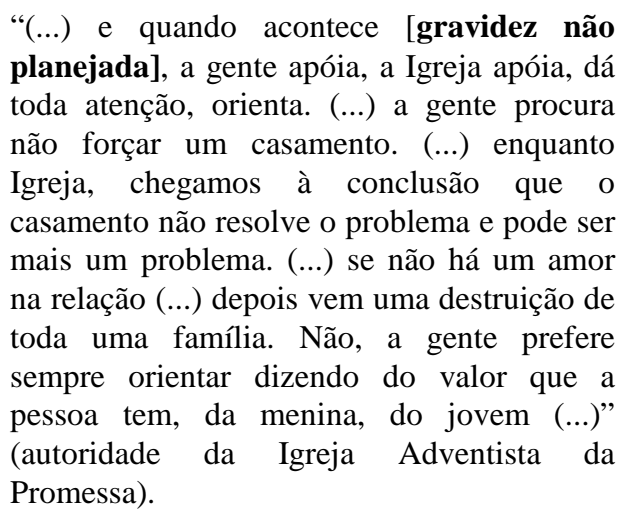

Um dos jovens evangélicos pentecostais entrevistados contou que não acatou o casamento como instrumento reparador da gravidez ocorrida em uma relação sexual ilícita com sua namorada. Escolheu não se casar, mesmo concordando que esta orientação religiosa é legítima, segundo os dogmas e normas para esses casos. Sua oposição ao ideal moral religioso, situação também encontrada em outras cenas e narrativas, indicou a possibilidade de escolha do sujeito diante de opções conflitantes, ou seja, a atuação de um "sujeito religioso".

Embora a idéia de acolhimento para os casos de gravidez não planejada esteja presente nas falas dos jovens, em todas as matrizes estes tendiam a ser mais radicais que suas autoridades quanto ao sentido negativo de uma gravidez ocorrida fora de hora, percebida como consequiência de "comportamento irresponsável" ou algo que aconteceria a alguém que está em contexto familiar "desestruturado".

"Foi uma amiga minha. (...) Ela, não é atirada! Sei lá, é meio mais maloqueira. (...) eu acho que o pensamento dela sobre sexo, essas coisas, mais aberta (...) ela não tá nem aí. (...) Ela é novinha, acho que tem 16 anos. (...) Essas meninas que não têm religião, que o pai e a mãe são distantes, entendeu? (... brigam muito (...) eu acho que a religião ajudaria" (jovem católica).

Os jovens das religiões afro-brasileiras também associaram a gravidez não-planejada ao comportamento irresponsável, um "vacilo" em relação ao uso de métodos contraceptivos, mas também a um ritual de passagem para um ciclo de responsabilidade. A gravidez não planejada é um perigo que muitos entrevistados consideravam distante, embora tenham relatado episódios e cenas ocorridos nos seus círculos de relações - com a irmã, prima, amigas, colegas da escola e da comunidade religiosa.

Para todos os jovens entrevistados, assumir a gravidez era a única possibilidade, o caminho para que se ocupe outro lugar, o de mãe responsável pela gestação, pelo cuidado e educação de seu filho. Algumas das falas sobre gravidez não planejada foram seguidas de comentários sobre o aborto, antes mesmo de o tema ser abordado. $\mathrm{O}$ aborto foi significado como "pecado" para os religiosos cristãos e/ou como problema social e de saúde apenas para algumas autoridades entrevistadas. A gravidez fora de hora deve ser evitada a todo custo e as autoridades assumiam-se como aconselhadoras orientando sobre suas consequiências. De modo geral, todos os religiosos entrevistados demonstraram rejeição total ao aborto, significado como um "erro" condenado pelas autoridades e jovens de todas as matrizes. O aborto nos casos previstos na legislação (estupro e risco de vida para mãe) foi interpretado como aceitável por apenas algumas autoridades entrevistadas.

Para jovens umbandistas e do Candomblé, assim como para mães e pais-de-santo, o aborto foi rejeitado porque implica na interrupção do curso da vida previsto nas leis de reencarnação espiritual, com conseqüências importantes para a trajetória das pessoas envolvidas e também para sua espiritualidade. Para religiosos evangélicos e católicos, o aborto foi também significado como um ato que "interrompe a vida", interpretado como "grave pecado". Apesar da condenação ao aborto, o acolhimento foi descrito em muitos casos e cenas em que se contextualizou a escolha pelo procedimento com a indicação de preocupação em não julgar precipitadamente.

Entre todas as autoridades entrevistadas, apenas uma relativizou uma condenação a priori do aborto. Declarou que essa seria uma possibilidade de escolha, considerando-se o contexto da gravidez. Essa autoridade umbandista admitiu estar em desacordo com as orientações religiosas tradicionais, dialogando como sujeito da sua religiosidade, sem conflito aparente com os dogmas e sem se sentir desacreditada na sua legitimidade. É importante lembrar que as religiões afro-brasileiras, especialmente a Umbanda, caracterizam-se pela autonomia nuclear de cada espaço religioso, de cada linhagem familiar - quando há linhagens na Umbanda (Negrão, 1996). Os dogmas 
sofrem a marca de cada pai ou mãe-de-santo, abrindo ou restringindo o espaço para a transgressão, para maior ou menor rigidez da hierarquia nos terreiros e centros, contexto com o qual a pessoa, como sujeito da sua religiosidade, deve lidar.

Todos os pentecostais afirmaram que somente Deus tem direito sobre a vida, e algumas falas apóiam a criminalização do aborto, concebendo-o como assassinato e crime. Nas cenas narradas, os personagens mais comuns eram as mulheres, geralmente condenadas a priori. Os homens estavam quase sempre ausentes das cenas relatadas. Alguns relatos justificavam a rejeição ao aborto com base na crença da vida desde a concepção - pois sendo vida, não admite interrupção.

\section{"É um assassinato (...). Independente da forma que ela foi gerada, nós não temos o direito de tirar a vida. O que a Bíblia nos orienta é isso, que Deus é que dá a vida e ele é o único que tem o poder de tirá-la. Independente de como aconteceu. Se aconteceu nós precisamos esperançar em Deus, deixar nascer e tomar as providências cabíveis para criar, educar, ensinar e formar" (autoridade da Igreja Adventista da Promessa).}

Como então "acolher"? Mesmo os criminosos, segundo os entrevistados, deveriam ser recebidos por Deus ou pelas divindades para abrandar e expiar seu sofrimento. Assim, em todas as matrizes há ritos (e punições) que permitiriam chegar ao perdão. Nas comunidades evangélicas e católicas, a mulher que aborta era recebida, mas como pecadora, condição que independe da pessoa ou da situação vivida. Chega antecipando sua culpa e ocupando a posição que pode ampliar a sua estigmatização e seu sofrimento. Alguns jovens atribuíram ao aborto uma irresponsabilidade ainda maior que aquela atribuída à gravidez não planejada. Reproduziram o discurso das autoridades a que recorriam para justificar sua própria condenação. Alguns jovens da Umbanda e do Candomblé, por outro lado, indicaram mais tolerância com o aborto em determinados contextos. Embora reconhecessem sua condenação pelos dogmas e orientação das autoridades religiosas afro-brasileiras, com as quais concordam, alguns jovens admitiram que essa poderia ser uma escolha.

Importante destacar que, apesar de todos os jovens entrevistados parecerem mais intolerantes que as suas autoridades mais velhas em relação ao aborto, o acolhimento apareceu nas suas falas em relação à mulher concreta que pratica o aborto. No caso dos evangélicos, acolher implica em dar oportunidade para que a mulher se reconheça como pecadora e deseje atingir o perdão. Embora observássemos nuanças e posições distintas entre os jovens religiosos entrevistados, foi possível identificar uma homogênea recusa ao aborto sobrepondo-se às pequenas demonstrações de tolerância. A oposição ao aborto, mesmo no caso de gravidez resultante de estupro, repetiu-se nas narrativas de rapazes e moças socializados na Umbanda, na Igreja Adventista, na Anglicana. No depoimento das moças católicas, a oposição à descriminalização do aborto apareceu associada ao temor de que fosse utilizado como método contraceptivo. Jovens pentecostais defenderam a contracepção como estratégia de planejamento familiar (apenas no casamento) e reproduziram uma forte condenação ao aborto.

Entre os rapazes e moças católicos, umbandistas e moças do Candomblé a associação com aborto era com a não-utilização de métodos contraceptivos na relação sexual; coincidentemente os jovens da Umbanda e do Candomblé indicaram maior conhecimento e valorização do discurso da saúde pública sobre a prevenção das DSTs/aids.

\section{CONSIDERAÇÕES FINAIS}

Os jovens entrevistados de diversas comunidades, mediante autorização ou indicação de lideranças mais velhas que reconheciam como suas autoridades religiosas, compreendem a sexualidade com sentidos que expressam a intensidade da tensão entre os diversos discursos com que convivem, articulando a moral e tradição religiosa com valores e discursos contemporâneos. Os sentidos e significados atribuídos à sexualidade, à iniciação sexual, ao sexo antes do casamento e à homossexualidade, à gravidez não planejada e ao aborto, às vezes tornam mais flexíveis a moralidade tradicional e as regras predominantes no discurso religioso; em outros momentos, tendem a reforçar significações mais fundamentalistas e baseadas numa rígida moralidade.

Diante dos temas abordados nas entrevistas, os jovens indicaram reconhecer pelo menos dois distintos códigos normativos, pelos quais eram também interpelados: leis divinas, que se somam aos valores construídos por esses jovens na subjetividade compartilhada na sua comunidade religiosa, e normas para convívio social mais amplo - sejam estas discursos tecnocientíficos, como o discurso da educação em saúde, sejam códigos consolidados na legislação - leis sobre aborto ou associadas ao direito à 
não-discriminação. Reconheciam e buscavam o cumprimento de códigos que, em algumas situações, podem ter orientações opostas. Como sujeitos de sua religiosidade (sujeitos religiosos), em algum episódio e cena de sua vida cotidiana identificaram as distintas orientações presentes nos diferentes códigos e as colocaram em tensão ou, eventualmente, fizeram-nas dialogar.

Pastores e a bíblia orientam mais fortemente a vida de evangélicos pentecostais. Entre os católicos, os sacerdotes podem ter sua autoridade diluída e educadores religiosos da comunidade assumem um lugar importante, mantendo eventualmente uma postura crítica em relação às orientações do Papa. Ainda que reconhecido por eles como a autoridade máxima da Igreja, os jovens não aceitam todas as suas orientações, que consideram antiquadas. Abrem mão da lei de inspiração divina para dar lugar a outros padrões sociais contemporâneos, aos discursos que valorizam o uso do preservativo e de métodos contraceptivos, além de serem abertos a diversas orientações sexuais e ao sexo antes do casamento. Muitos dos jovens entrevistados, ao estabelecerem relação com suas autoridades religiosas, reforçavam cotidianamente sua identidade como parte de um grupo religioso e, ao mesmo tempo, singularizavam sua experiência autônoma como sujeitos de sua religiosidade e sexualidade.

Foi interessante notar como entre os religiosos afro-brasileiros a valorização dos direitos sexuais e reprodutivos e, abertamente, do discurso da prevenção, foi inspirada pela autoridade representada na figura do pai ou mãe-de-santo. Jovens umbandistas e do Candomblé aprenderam com suas autoridades a lidar com a noção de direitos associada à superação da discriminação religiosa, que marca a história dessas religiões no Brasil.

Ao descrever e refletir criticamente sobre a relação entre heteronomia religiosa e autonomia do sujeito no campo da religiosidade e da sexualidade, este artigo pretendeu contribuir para subsidiar políticas públicas que possam considerar as especificidades da juventude religiosa. Pretendeu também lidar com os desafios daí decorrentes para a elaboração de programas que pretendem levar em conta o discurso religioso do ponto de vista da religiosidade dos sujeitos participantes das políticas públicas nessa área. Com base nesse estudo, avaliamos que a noção de "sujeito religioso" permite descrever a experiência dos entrevistados ao mesmo tempo em que é interessante para planejar a colaboração com grupos religiosos na perspectiva dos direitos humanos, garantindo aos jovens das comunidades e em processo de socialização sexual o direito à prevenção; ou seja, essa noção pode ser operativa para garantir o direito à informação completa sobre métodos contraceptivos e às tecnologias de prevenção das DSTs/aids, e sobre seus direitos, como o direito à saúde e à não-discriminação (Paiva et al., 2006).

Há várias possibilidades de trabalho com prevenção inspirada pelos direitos humanos. A abordagem multicultural dos direitos humanos, proposta por Boaventura Souza Santos (2003), pode ser mais produtiva, por respeitar cada concepção de dignidade humana, valorizar a diferença e permitir interpretar o universo religioso - como diria Valle (2005) - pela apropriação que os sujeitos fazem dos seus códigos de moralidade. Nessa perspectiva, o diálogo com as comunidades religiosas no campo da promoção da saúde sexual deverá significá-las e incorporá-las como sujeitos de direitos e compreendê-las também como sujeitos religiosos, lançando mão da hermenêutica diatrópica definida por Santos (2003); deverá garantir um modo de compreensão e interpretação em diálogo que seja capaz de reconhecer que cada cultura (e concepção de dignidade) é sempre incompleta, se observada da perspectiva de outra.

Se valorizarmos o diálogo que o sujeito religioso articula entre os discursos sobre sexualidade que frequientam seu cotidiano, buscando lidar com a tensão e o conflito entre tradição e modernidade no plano individual, no plano programático estaremos aprendendo o caminho para o diálogo com as comunidades das diferentes matrizes e suas concepções próprias de heteronomia moral religiosa. A noção de "acolhimento", que emergiu das religiosidades de todas as matrizes e merece ser mais bem investigada e analisada, apareceu como um momento interessante, em que um diálogo nessa perspectiva vem se impondo na experiência viva da religião.

Ao longo desta análise foi possível verificar que mesmo a religiosidade de comunidades já sensibilizadas para a resposta ao HIV/Aids implica desafios para o fortalecimento da laicidade em sociedades democráticas. $\mathrm{O}$ aborto e a homossexualidade são os temas que carregam as maiores marcas da heteronomia moral religiosa, interpeladas pela tensão entre modernidade e tradição. Nesses temas o discurso religioso é mais duro e resistente ao discurso dos direitos sexuais e direitos reprodutivos, cuja promoção e proteção têm sido incluídas como parte da definição de saúde sexual (WHO, 2006).

Os resultados apontaram também que a complexidade da dinâmica relação entre ethos privado e a heteronomia religiosa deve ser tema aprofundado por outros estudos que discutam as tensões do diálogo entre 
religiosidade e sexualidade, especialmente no caso da juventude.

Este estudo nos ajudou a consolidar a noção de que, como sujeitos do cotidiano, somos mobilizados por contextos intersubjetivos e capazes de combinar repertórios, estabelecer diálogos entre discursos distintos sobre religiosidade (como sujeitos religiosos), sobre sexualidade (como sujeitos sexuais), sobre direitos, desejos ou projetos (com sujeitos de direito). Todos são, portanto, capazes de construir suas trajetórias de vida no campo da sexualidade interpretando e recriando distintos discursos reguladores de maneira autônoma e atualizada para o seu contexto sociocultural e político. Assim todos os brasileiros, independentemente de sua religião, devem ser considerados no planejamento de políticas públicas que promovem a saúde e os direitos sexuais.

\section{REFERÊNCIAS}

Bozon, M. (2003). Sexualidade e conjugalidade - a redefinição das relações de gênero na França contemporânea. Cadernos Pagu, 20,131-156.

Brandão, C. R. (2004). Fronteira da Fé - alguns sistemas de sentido, crenças e religiões no Brasil de hoje. Estudos Avançados, 18(52), 261-288.

Brandão, E. R. (2006). Gravidez na adolescência: um balanço bibliográfico. Em M. L. Heilborn, E. M. L. Aquino, D. R. Knauth \& M. Bozon (Orgs.), O aprendizado da sexualidade reprodução e trajetórias sociais de jovens brasileiros (pp. 6195). Rio de Janeiro: Fiocruz \& Garamond Universitária.

Burity, J. A. (2001). Religião e política na fronteira: desinstitucionalização e deslocamento numa relação historicamente polêmica. Revista de Estudos da Religião, 4, 2745.

Citelli, M. C. (2005). A pesquisa sobre sexualidade e direitos sexuais no Brasil (1990-2002) - revisão crítica. Centro Latinoamericano em sexualidade e direitos humanos - IMS/UERJ. Rio de Janeiro: CEPESC.

Cunha, O. M. (2000). Depois da festa: movimentos negros e "políticas de identidade" no Brasil. Em S. E. Alvarez, E. Dagnino \& A. Escobar (Org.), Cultura e política nos movimentos sociais latino-americanos - novas leituras (pp. 333-382). Belo Horizonte: Editora UFMG.

Duarte, L. F. D. (2006). A guisa de introdução: o que perguntamos à família e à religião? Em L. F. D. Duarte, M. L. Heilborn, M. L. Barros \& Peixoto, C. (Orgs.), Família e Religião (pp. 7-13). Rio de Janeiro: Contra Capa.

Duarte, L. F. D., Jabor, J. M., Gomes, E. C., \& Luna, N. (2006). Família, reprodução e ethos religiosos: subjetivismo e naturalismo como valores estruturantes. Em L. F. D. Duarte, M.
L. Heilborn, M. L. Barros \& C. Peixoto (Orgs.), Família e Religião (pp. 15-50). Rio de Janeiro: Contra Capa.

Farris, J. R. (2008). Autoridades morais no comportamento sexual humano: implicações para a religião e a psicologia. Em I. G. Arcuri \& M. Ancona-Lopez (Orgs.), Temas em Psicologia da Religião (pp. 115-136). São Paulo: Vetor.

Gruman, M. (2005). O lugar da cidadania: Estado moderno, pluralismo religioso e representação política. Revista de Estudos da Religião, 1, 95-117.

Heilborn, M. L. (2006). Ente as tramas da sexualidade brasileira. Revista de Estudos Feministas, 14(1), 43-59.

Negrão, L. N. (1996). Entre a cruz e a encruzilhada. São Paulo: EDUSP.

Paiva, V., Calazans, G., Venturi, G., \& Dias, R. (2008). Idade e uso de preservativo na iniciação sexual de adolescentes brasileiros. Revista de Saúde Pública, 42(suplemento 1), 45-53.

Paiva, V., Pupo, L. R., \& Barboza, R. (2006). O direito à prevenção e os desafios da redução da vulnerabilidade ao HIV no Brasil. Revista de Saúde Pública, 40(suplemento), 109-119.

Paiva, V. (2005). Analyzing sexual experiences through 'scenes': A framework for the evaluation of sexuality education. Sex Education, 4(5), 345-359.

Paiva, V., Ayres J. R., \& França Jr. I. (2003). Expanding the flexibility of normative patterns in youth sexuality and prevention program. Sexuality Research \& Social Policy Journal of NSRC, 1(1), 83-97.

Paiva, V. (1999). Cenas sexuais, roteiros de gênero e sujeito sexual. Em R. M. Barbosa \& R. Parker (Orgs.), Sexualidades pelos avesso: direitos, identidades e poder (pp. 249-269). Rio de Janeiro: Editora 34.

Santos, B. S. (2003). Por uma concepção multicultural de direitos humanos. Em B. S. Santos, Reconhecer para libertar - os caminhos do cosmopolitismo multicultural (pp. 429-461). Rio de Janeiro: Civilização Brasileira.

Santos, E. S., \& Mandarino, C. M. (2005). Juventude e Religião: cenários no âmbito do lazer. Revista de Estudos da Religião, 3, 161-177.

Valle, J. E. R. (2005). Religião e espiritualidade: um olhar psicológico. Em M. M. Amatuzzi (Org.), Psicologia $e$ Espiritualidade (pp. 59-108). São Paulo: Paullus.

Watanabe, T. H. B. (2005). Caminhos e histórias: a historiografia do protestantismo na Igreja Presbiteriana do Brasil. Revista de Estudos da Religião, 1, 15-30.

WHO - World Health Organization (2006). Defining Sexual Health: Report on technical consultation on sexual health 2002 (Sexual Health Document Series). Geneva, Switzerland.

Recebido em 14/06/2008 Aceito em 19/08/2008

Endereço para correspondência : Cristiane Gonçalves da Silva. Rua Antonio Doll de Moraes, 149, ap. 1009, Diadema, CEP 09920-540, São Paulo-SP.E-mail: crica@usp.br 